\title{
Gondi Language
}

National Cancer Institute

\section{Source}

National Cancer Institute. Gondi Language. NCI Thesaurus. Code C153934.

A South-Central Dravidian language, spoken chiefly in the Indian states of Madhya

Pradesh, Gujarat, Telangana, Maharashtra, Chhattisgarh, and Andhra Pradesh. 